\title{
Interleukin-12 and Interleukin-18 Synergistically Induce Murine Tumor Regression Which Involves Inhibition of Angiogenesis
}

\author{
Christina M. Coughlin," Kevin E. Salhany, ${ }^{ף}$ Maria Wysocka, ${ }^{\star}$ Etsuko Aruga,‡ Holly Kurzawa, Alfred E. Chang, ${ }^{\S}$ \\ Christopher A. Hunter, ${ }^{\star \star}$ Jonathan C. Fox, ${ }^{\ddagger \neq\|\|}$ Giorgio Trinchieri, ${ }^{\star}$ and William M.F. Lee ${ }^{\star \neq \neq \S \S\|\|}$ \\ *The Wistar Institute, Philadelphia, Pennsylvania 19104; ${ }^{\ddagger}$ Department of Internal Medicine, National Cancer Center Hospital, 6-5-1 \\ Kashiwanoha, Chiba 277, Japan; ${ }^{\S}$ Department of Surgery, University of Michigan, Ann Arbor, Michigan 48109; "Biomedical Graduate

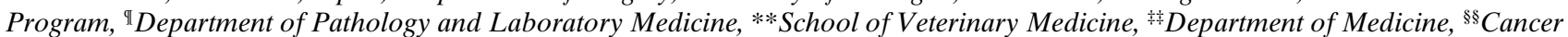 \\ Center, and ${ }^{\| I}$ Institute for Human Gene Therapy, University of Pennsylvania, Philadelphia, Pennsylvania 19104
}

\begin{abstract}
The antitumor effect and mechanisms activated by murine IL-12 and IL-18, cytokines that induce IFN- $\gamma$ production, were studied using engineered SCK murine mammary carcinoma cells. In syngeneic A/J mice, SCK cells expressing mIL-12 or mIL-18 were less tumorigenic and formed tumors more slowly than control cells. Neither SCK.12 nor SCK.18 cells protected significantly against tumorigenesis by distant SCK cells. However, inoculation of the two cell types together synergistically protected $70 \%$ of mice from concurrently injected distant SCK cells and 30\% of mice from SCK cells established $3 \mathrm{~d}$ earlier. Antibody neutralization studies revealed that the antitumor effects of secreted mIL-12 and mIL-18 required IFN- $\gamma$. Interestingly, half the survivors of SCK.12 and/or SCK.18 cells developed protective immunity suggesting that anti-SCK immunity is unlikely to be responsible for protection. Instead, angiogenesis inhibition, assayed by Matrigel implants, appeared to be a property of both SCK.12 and SCK.18 cells and the two cell types together produced significantly greater systemic inhibition of angiogenesis. This suggests that inhibition of tumor angiogenesis is an important part of the systemic antitumor effect produced by mIL-12 and mIL-18. (J. Clin. Invest. 1998. 101:1441-1452.) Key words: cytokine • interleukin-12 • interleukin-18 • immunotherapy • tumor angiogenesis
\end{abstract}

\section{Introduction}

Different approaches to tumor immunotherapy have been shown to be effective in murine models of cancer. Tumor cell immunization offers the advantage that all potential tumor antigens are present, and they are one of the few vaccine options available when specific tumor antigens have not been identified. The strategies attempt to enhance host responses to tumor antigens by creating a local environment favorable for antigen presentation and immunological recognition of tumor

Address correspondence to William M.F. Lee, CRB 663, 415 Curie Blvd., Philadelphia, PA 19104. Phone: 215-898-0258; FAX: 215-5737912.

Received for publication 20 August 1997 and accepted in revised form 21 January 1998.

J. Clin. Invest.

(C) The American Society for Clinical Investigation, Inc. 0021-9738/98/03/1441/12 \$2.00

Volume 101, Number 6, March 1998, 1441-1452

http://www.jci.org cells. Many involve engineering tumor cells to express immunostimulatory cytokines, such as interleukin-12 (IL-12) (1-3). Several different murine tumors engineered to express mIL-12 induce enhanced cell-mediated immunity and tumor-specific rejection responses in syngeneic mice $(1,3)$. Nonmalignant fibroblasts engineered to secrete murine IL-12 (mIL-12) ${ }^{1}$ have been injected with native tumor cells to achieve similar results, presumably through paracrine activities of the cytokine (4). How IL-12 achieves these antitumor effects is less certain, in part because its pleiotropic effects make it difficult to ascribe antitumor effectiveness to any individual mechanism. IL-12 favorably alters the host-tumor relationship through any of several direct and indirect effects on lymphoid and nonlymphoid cells (5). It enhances cellular immune mechanisms by favoring the differentiation of $\mathrm{CD}^{+}$helper $\mathrm{T}$ cells towards the Th1 subset (6), and upregulating MHC expression $(7,8)$. Th1 cells secrete IL-2 and interferon- $\gamma$ (IFN- $\gamma$ ) which are cytokines that facilitate the proliferation and/or activation of $\mathrm{CD}^{+}$cytolytic T cells (CTL), natural killer (NK) cells and macrophages, all of which can contribute to tumor regression (8-10). Many of IL-12's effects, both therapeutic and toxic, have been shown to depend on the IL-12-stimulated IFN- $\gamma$ secretion by T and NK cells (10-13). IFN- $\gamma$ enhances many antigen-nonspecific immune and nonimmune mechanisms, many of which favor tumor regression. These include direct cytotoxicity in combination with TNF- $\alpha$ (14), a slowing of cellular proliferation (14), induction of nitric oxide production $(15,16)$ and inhibition of angiogenesis, which has received particular attention of late (17-20). Thus, IL-12 potentially activates a variety of antitumor mechanisms, some of which are antigen-specific and some of which are not.

IFN- $\gamma$ release is also induced by another, more recently identified cytokine, IL-18 (21), also called interferon- $\gamma$-inducing factor (IGIF) (22). IL-18 is produced by Kupffer cells and activated macrophages, promotes IFN- $\gamma$ release (23), and inhibits the production of IL-10 by activated T cells $(21,22)$. IL18 augments both murine and human NK cytotoxicity $(21,22)$ and stimulates Fas ligand-mediated tumor cell cytotoxicity by NK cells (24). While IL-18 and IL-12 induce similar responses, particularly those promoting cellular immunity and IFN- $\gamma$ release, the two cytokines do not have identical effects inasmuch as they synergistically induce $\mathrm{T}$ cell production of IFN- $\gamma$ in vitro (23). The activities of IL-18 suggest that it might have antitumor activity and, recently, recombinant mIL-18 was shown

1. Abbreviations used in this paper: CTL, cytolytic T lymphocyte; IGIF, interferon- $\gamma$-inducing factor; mIL-12, murine interleukin-12; NK, natural killer; rmIL-12, recombinant murine interleukin-12; SCID, severe combined immunodeficiency disease. 
to enhance the survival of BALB/c mice bearing Meth $\mathrm{A}$ tumors (25).

The ability of both IL-12 and IL-18 to promote cell-mediated immune responses and their ability to synergistically induce production of IFN- $\gamma$ led us to examine the antitumor effect of these two cytokines singly and in combination. This was done using SCK murine mammary carcinoma cells engineered to secrete mIL-12 (SCK.12 cells) or mIL-18 (SCK.18 cells). We found that while each cytokine had measurable antitumor effects, which were sometimes quite pronounced, the two together were much more effective at providing systemic antitumor protection. Examination of the mechanisms of tumor rejection indicated that inhibition of tumor angiogenesis rather than antigen-specific immune responses was more likely to account for the antitumor effects seen.

\section{Methods}

Mice and cell lines. Female A/J mice, 6-8 wk old, were purchased from The Jackson Laboratory (Bar Harbor, ME). Female severe combined immunodeficiency disease (SCID) mice, $6 \mathrm{wk}$ old, were bred at the Wistar Institute. All animals were maintained in microisolator cages and handled under aseptic conditions. The SCK mammary carcinoma cell line (gift from Dr. J.G. Rhee, University of Maryland, Baltimore, MD) (26) was derived from a tumor that spontaneously arose in an A/J mouse ( $\left.\mathrm{H}-2^{\mathrm{a}}\right)$ and is maintained in RPMI 1640 medium supplemented with $10 \%$ FCS and penicillin/streptomycin. They are poorly immunogenic and only $11 \%$ of mice are protected from a challenge of $10^{5}$ live SCK cells after subcutaneous vaccination once or three times with $10^{6}$ irradiated SCK cells (data not shown). Sa-1 sarcoma cells, also syngeneic in A/J mice, were a gift from Dr. Susan Ostrand-Rosenberg (University of Maryland, Baltimore, MD) (27), and were maintained in Dulbecco's MEM supplemented with $15 \%$ FCS and $5 \%$ horse serum.

Vectors and cell transduction. To create SCK cells that express murine IL-12 (SCK.12 cells), wild-type SCK cells were transfected with plasmid pWRG (28) that contains both the p35 and p40 subunit cDNAs of mIL-12 linked by an internal ribosome entry site and under the control of the CMV promoter. Transfected cells were selected by limiting dilution and screening of individual clones by RIA.

IL-18 cDNA was obtained by reverse transcription-PCR using RNA prepared from spleens of LPS-treated mice based on the published sequence of mIL-18/IGIF (22) using the primers: $5^{\prime}$ (upper): GGCCCAGGAACAATGGCT and $3^{\prime}$ (lower): CCCTCCCCACCTAACTTTGAT. The mIL-18 cDNA clone we used was sequenced to confirm normal coding potential and subcloned into the pLXSN retrovirus to create $\mathrm{pL}(\mathrm{IL}-18) \mathrm{SN}$. $\psi_{\text {cre }}$ packaging cells were transfected by the calcium phosphate method and selected in G418 (400 $\mu \mathrm{g} / \mathrm{ml}$ ) to create resistant colonies that produce $\mathrm{L}(\mathrm{mIL}-18) \mathrm{SN}$ retrovirus. Supernatants from these cells were used to infect SCK cells in media containing $8 \mu \mathrm{g} / \mathrm{ml}$ polybrene. Individual G418-resistant SCK clones (e.g., SCK.18A cells) were assayed for mIL-18 expression by Northern analysis and RIA to determine IL-18 expression. To create SCK cells expressing higher levels of mIL-18 (e.g., SCK.18C cells), the mIL-18 cDNA was subcloned into the pEF2 vector which contains a neo ${ }^{\mathrm{r}}$ gene (provided by S. Pestka, UMDNJ, Piscataway, NJ) and transfected into SCK cells by the calcium phosphate method. G418 resistant clones were analyzed by Northern analysis and RIA to determine expression.

$I L-12, I L-18$, and IFN- $\gamma$ assays. IL-12 levels in SCK.12 cell supernatants were determined by RIA using monoclonal antibodies $(\mathrm{mAb})$ developed in our laboratory. 24-h supernatants were added to 96-well plates (Dynatech Laboratories, Inc., Chantilly, VA) coated with $5 \mu \mathrm{g} / \mathrm{ml} \mathrm{C} 17.8$ (anti-p40 mAb). After overnight incubation at $4^{\circ} \mathrm{C}$, plates were washed with PBS-Tween-20. ${ }^{125}$ I-labeled C18.2 (antip35 mAb) was added to each well and incubated for $6 \mathrm{~h}$ at $4^{\circ} \mathrm{C}$.
Bound ${ }^{125}$ I-labeled antibody was assayed in a microplate scintillation counter (Topcount; Packard Instrument Co., Meriden, CT).

IL-18 levels were determined by ELISA assay. To measure production of mIL-18/IGIF, a rabbit polyclonal antiserum specific for mIL-18 was generated by immunizing a rabbit with three doses of mIL-18 (100 $\mu \mathrm{g}$ per immunization). Purified recombinant mIL-18 was the generous gift of R. Kastelein (DNAX Research Institute, Palo Alto, CA). The pre-bleed could not detect IL-18 in Western blots nor did it neutralize the ability of IL-18 to stimulate NK cell production of IFN- $\gamma$. In contrast, the unfractionated antisera did detect rmIL-18 and mature mIL-18 in IFN- $\gamma$ activated macrophages by Western blot. Furthermore, this antiserum neutralized the ability of mIL-18 to enhance mIL-12-mediated production of IFN- $\gamma$ by NK cells (data not shown). A purified $\operatorname{IgG}$ fraction of the antisera was prepared (Harlan Bioscience, Madison, WI) and used as the basis for a two site ELISA as described previously (29). The sensitivity of this assay is $300 \mathrm{pg} / \mathrm{ml}$, and it did not detect IFN- $\gamma$, IL-12, IL- $1 \alpha$, or IL- $1 \beta$.

Blood samples were harvested by retro-orbital eye bleeds from three mice per experimental group. mIFN- $\gamma$ was determined for each sample by RIA as described previously (30). Serum samples were diluted 1:5 and added to 96-well plates (Dynatech Laboratories, Inc.) coated with $5 \mu \mathrm{g} / \mathrm{ml}$ of AN18 (anti-mIFN- $\gamma \mathrm{mAb}$ ). After overnight incubation at $4^{\circ} \mathrm{C}$, plates were washed in PBS-Tween. ${ }^{125} \mathrm{I}$-labeled XMG1.2 (anti-mIFN- $\gamma$ mAb) was added to each well and incubated for $6 \mathrm{~h}$ at $4^{\circ} \mathrm{C}$. Bound ${ }^{125}$ I-labeled antibody was assayed as described previously.

Tumorigenesis studies. Tumorigenesis studies using various SCK cells (SCK.18, SCK.12, or wild-type SCK cells) were carried out by injecting $2.5 \times 10^{4}$ viable cells subcutaneously in the flank of each $\mathrm{A} / \mathrm{J}$ or SCID mouse, unless other doses are indicated. The cells were obtained from cultures established from low-passage, frozen stocks $<1$ wk before injection, and the number of cells injected was based on the count of cells excluding trypan blue. To test for immunity in mice that survived their initial exposure to transduced SCK cells, the survivors were challenged with $10^{5}$ SCK cells. Mice were monitored daily for tumor growth, and killing was performed according to Institutional Animal Care and Use Committee guidelines.

In vivo neutralization of mIFN- $\gamma$ or mIL-12 in tumorigenesis studies was accomplished by injecting A/J mice with either XMG.6 anti-IFN- $\gamma \mathrm{mAb}$ antibody (gift from Alan Sher, National Institutes of Health, Bethesda, MD; 30) or C17.15 anti-IL-12 mAb at $0.5 \mathrm{mg}$ per injection per mouse on days $-1,1,3$, and 6 . Normal rat antibody (0.5 mg per injection per mouse; Sigma Chemical Co., St. Louis, MO) or PBS was injected into control mice on the same schedule. The ability of the anti-IFN- $\gamma$ and anti-IL-12 mAbs to deplete mice of IFN- $\gamma$ and IL-12 was shown previously (30).

Matrigel assay for angiogenesis. Angiogenesis assays were carried out by injecting A/J mice with $0.5 \mathrm{ml}$ Matrigel (Catalog \#40234; Collaborative Biomedical Products, Bedford, MA; reference 31) mixed on ice with either $10 \mathrm{ng}$ recombinant basic FGF (b-FGF) or $10^{5}$ SCK, SCK.12, or SCK.18 cells as the angiogenic stimulus. Matrigel was injected subcutaneously in the abdominal midline on day 0 in all experiments. Mice given recombinant mIL-12 were injected on days $-1,0,1,2$ and 3. Mice given XMG.6 anti-IFN- $\gamma$ mAb were injected on days $-1,1$, and 3 . Matrigel plugs were harvested on day 4 for photography or on day 6 for hemoglobin assay. Quantitation of hemoglobin was performed by the Drabkin method (32). Briefly, Matrigel pellets were harvested and all surrounding tissue was dissected away. Pellets were melted at $4^{\circ} \mathrm{C}$ and assayed for hemoglobin content (Drabkin's reagent kit; Sigma Diagnostics, St. Louis, MO). Different lots of Matrigel produce different levels of hemoglobinization, but within individual experiments, the differences were significant.

CTL assays. Spleens of A/J mice injected with SCK.12C, SCK.18A or SCK.12C plus SCK.18A cells were removed. Red blood cell depleted spleen cell suspensions were cocultured at $4 \times 10^{6}$ cells with $10^{5} \gamma$-irradiated $(20,000$ rads) SCK or HKB cells per well in 24-well plates in $2 \mathrm{ml}$ of RPMI 1640 supplemented with $5 \%$ heat inactivated FCS, 2-mercaptoethanol, $10 \mathrm{mM}$ HEPES, sodium pyruvate, nones- 
sential amino acids, and penicillin/streptomycin. Cultures were incubated for $5 \mathrm{~d}$. For the determination of cytolytic activity, $10^{6}$ SCK (NK-resistant targets) or YAC cells (NK-susceptible targets) were labeled with $100 \mu \mathrm{Ci}{ }^{51} \mathrm{Cr}$ for $90 \mathrm{~min}$ and washed three times in PBS. Effector cultures were harvested, washed three times with PBS, and coincubated with 5,000 labeled target cells at decreasing ratios (starting at 50:1). After $8 \mathrm{~h}$, chromium release was measured in $100 \mu \mathrm{l} \mathrm{su}-$ pernatant from each well. Specific lysis was calculated as follows: percent specific lysis $=100 \times($ mean experimental $\mathrm{cpm}-$ mean spontaneous $\mathrm{cpm} /($ mean maximum $\mathrm{cpm}$ - mean spontaneous $\mathrm{cpm})$. Splenocytes from SCK-vaccinated or immune mice restimulated with control HKB cells consistently generate cultures with background levels of SCK cytolytic activity. HKBs are cultured cells established from a spontaneously arising, noninvasive tumor in an aged, unmanipulated, female A/J mouse in our vivarium. They are MHC class $\mathrm{I}^{+}$ and are nontumorigenic in female $\mathrm{A} / \mathrm{J}$ mice after injection of up to $2 \times$ $10^{6}$ cells per mouse.

\section{Results}

Tumor formation by SCK tumor cells expressing mIL-12 (SCK.12 cells). SCK cells do not normally express IL-12 and were engineered to express both the p35 and p40 subunits of mIL-12 by transfection with a bicistronic expression vector. We obtained clones SCK.12A and SCK.12C that produce 1 and $12 \mathrm{ng}$ mIL-12/10 6 cells per $24 \mathrm{~h}$, respectively. When A/J mice were injected with $2.5 \times 10^{4}$ cells, all of those receiving SCK cells developed fatal tumors, whereas progressive tumors formed in $77 \%$ injected with SCK.12A cells and in $0 \%$ injected with SCK.12C cells (Table I and Fig. 1). SCK.12A tumors appeared about 6-8 d later than SCK tumors which resembles the delay in SCK tumor appearance in mice treated with re-

Table I. The Effect of IL-12 or IL-18 Secretion by SCK Cells on Tumorigenicity

\begin{tabular}{lccc}
\hline Tumor cells injected* $^{*}$ & Mice with tumors $^{\ddagger}$ & Regressors $^{\S}$ & Time to tumor \\
\hline SCK & & & \\
$\quad 2.5 \times 10^{4}$ cells & $25 / 25(100 \%)$ & $0 / 25$ & $7.5 \pm 1.9$ \\
$\quad$ SCK.12A & & & \\
$\quad 2.5 \times 10^{4}$ cells & $17 / 22(77 \%)$ & $0 / 17$ & $13.5 \pm 4.1$ \\
SCK.12C & & & \\
$\quad 2.5 \times 10^{4}$ cells & $0 / 16(0 \%)$ & - & - \\
$10^{6}$ cells & $3 / 5(60 \%)$ & $3 / 3$ & $8.0 \pm 0.6$ \\
SCK.18A & & & \\
$\quad 2.5 \times 10^{4}$ cells & $19 / 28(68 \%)$ & $0 / 19$ & $13.0 \pm 3.1$ \\
SCK.18C & & & \\
$2.5 \times 10^{4}$ cells & $3 / 10(30 \%)$ & $0 / 3$ & $17.0 \pm 2.1$ \\
$10^{5}$ cells & $4 / 5(80 \%)$ & $0 / 4$ & $13.5 \pm 1.7$ \\
$10^{6}$ cells & $5 / 5(100 \%)$ & $0 / 5$ & $12.0 \pm 2.3$ \\
& & & \\
\hline
\end{tabular}

* Tumor cells of the indicated type were injected subcutaneously. The dose of cells is indicated below. ${ }^{\ddagger}$ Mice with tumors: indicated by the number of mice developing tumors/the number of mice in the cohort. The percentage of mice developing tumors is indicated in parentheses. These results were compiled from six separate experiments. ${ }^{\S}$ The number of regressors is indicated by the number of tumors regressing/the number of tumors that developed in that group. "Time to tumor: number of days after the animal was injected with cells before the tumor became detectable. These data are expressed as the median number of days for all mice in the group that developed tumors \pm SD.

\section{A A/J mice}

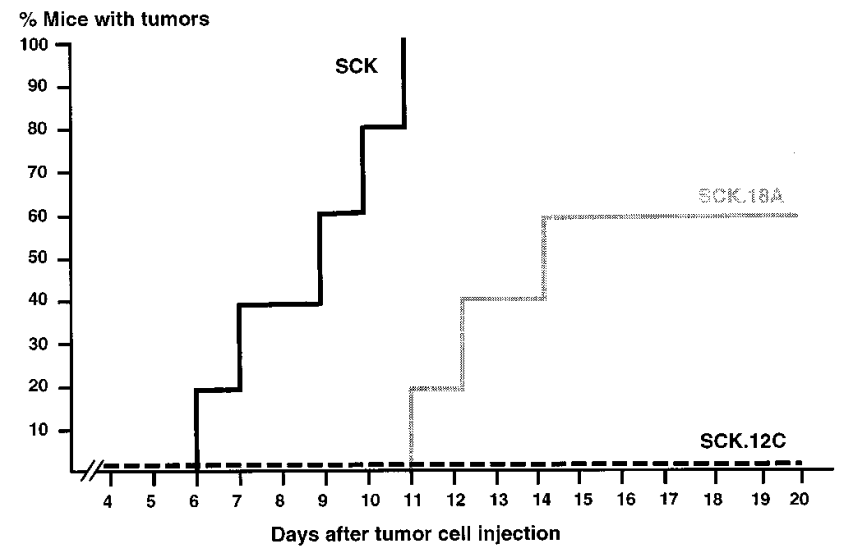

\section{B SCID mice}

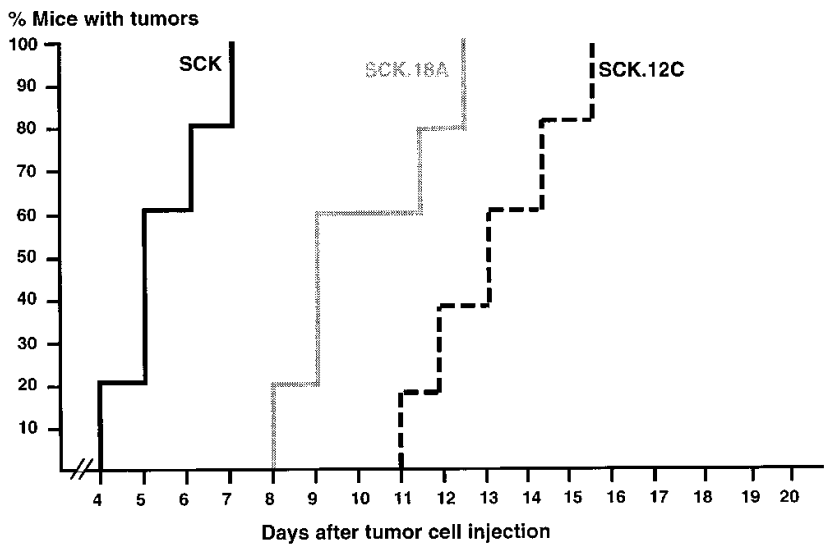

Figure 1. Tumor development in $\mathrm{A} / \mathrm{J}$ or SCID mice receiving SCK.12C or SCK.18A cells. Cohorts of A/J $(A)$ or SCID $(B)$ mice were injected with $2.5 \times 10^{4} \mathrm{SCK}$, SCK.18A or SCK.12C cells on day 0 and tumor formation was monitored daily. Solid black lines represent tumorigenesis in mice injected with SCK cells; solid gray lines represent tumorigenesis in mice injected with SCK.18A cells; dashed black lines represent tumorigenesis in mice injected with SCK.12C cells. There were five mice in each group, and these data are from a single, representative experiment.

combinant murine interleukin-12 (rmIL-12) (11). SCK.12C cells did not form progressive tumors even when the dose of cells was increased to $10^{6}$ cells; $60 \%$ of these mice developed small tumors after about $7 \mathrm{~d}$ that spontaneously regressed over the next 3-4 d (regressors in Table I; a similar phenomenon was described in reference 2). These data indicate that the reduced tumorigenicity of SCK cells secreting mIL-12 depends on the level of secretion. To determine whether the failure of SCK.12C cells to form progressive tumors was an intrinsic property of the cells or was due to a host response, we injected $2.5 \times 10^{4}$ SCK.12C cells into SCID mice. All developed progressive tumors which appeared significantly later $(\sim 7 \mathrm{~d})$ than SCK tumors in SCID mice (Fig. 1). These results indicate that $\mathrm{T}$ and/or B cells were required to prevent SCK.12C tumors, but that cells present in SCID mice, such as NK cells, were able to delay tumor formation.

To determine if IL-12-stimulated production of IFN- $\gamma$ was responsible for the observed antitumor activity, antibody neu- 
Table II. Effect of IFN- $\gamma$ or IL-12 Neutralization on the Antitumor Response Induced by IL-12 or IL-18

\begin{tabular}{|c|c|c|c|}
\hline Tumor cells injected* & Antibody $y^{\ddagger}$ & Mice with tumors ${ }^{\S}$ & Time to tumor \\
\hline SCK.12C & None & $0 / 5$ & - \\
\hline SCK.12C & NRA & $0 / 5$ & - \\
\hline SCK.12C & $\alpha-\mathrm{IFN}-\gamma$ & $4 / 5$ & $8.0 \pm 1.8$ \\
\hline SCK.12C & $\alpha-\mathrm{IL}-12$ & $5 / 5$ & $10.5 \pm 2.9$ \\
\hline SCK.18C & None & $1 / 5$ & 17 \\
\hline SCK.18C & NRA & $2 / 5$ & $16.0 \pm 2.8$ \\
\hline SCK.18C & $\alpha-\mathrm{IFN}-\gamma$ & $5 / 5$ & $7.0 \pm 1.6$ \\
\hline SCK.18C & $\alpha-\mathrm{IL}-12$ & $2 / 5$ & $15.0 \pm 2.8$ \\
\hline
\end{tabular}

* Tumor cells of the indicated type were injected subcutaneously in the flank region of the mouse. The dose of cells is $2.5 \times 10^{4}$ cells per mouse. These data are from one experiment. ${ }^{\ddagger}$ Mice were injected with antibodies indicated on days $-1,1,3$, and 6 . $N R A$, normal rat antibody. Mice receiving no antibodies were injected with PBS alone on the same schedule. ${ }^{\S}$ Mice with tumors: the number of mice developing tumors/the number of mice in the cohort. "Time to tumor: the number of days after the animal was injected with cells before the tumor became detectable. These data are expressed as the median number of days for all mice in the group that developed tumors \pm SD.

tralization studies were performed (Table II). After injections of XMG.6 anti-IFN- $\gamma$ mAb into mice injected with SCK.12C cells, four out of five developed progressive tumors. This resembled the uniform development of SCK.12C tumors in mice given anti-mIL-12 antibody and contrasted with the lack of tumors in mice given control or no antibody. Importantly, treatment of mice with anti-IFN- $\gamma$ antibody abrogated the delay in tumor development normally seen with SCK.12 cells (Table II) and with rmIL-12 therapy (11), suggesting that IFN- $\gamma$ mediates the delay in tumor development and plays a crucial early role in host protection.

Tumor formation by SCK tumor cells expressing mIL-18 (SCK.18 cells). SCK cells do not produce IL-18 mRNA detectable by Northern analysis or IL-18 protein detectable by ELISA. We engineered SCK cells to express mIL-18 and studied two clones, SCK.18A and SCK.18C. By Northern analysis, SCK.18C cells expressed significantly more recombinant mIL-18 mRNA than SCK.18A cells (data not shown), and by RIA SCK.18C cells secreted $0.51 \mathrm{ng}$ mIL- $18 / 10^{6}$ cells per $24 \mathrm{~h}$ while SCK.18A cells secreted $<0.30 \mathrm{ng} / 10^{6}$ cells per $24 \mathrm{~h}$. Both SCK.18A and SCK.18C cells have in vitro growth characteristics similar to SCK cells, but when $\mathrm{A} / \mathrm{J}$ mice were injected with $2.5 \times 10^{4}$ SCK. 18 A or SCK.18C cells, only 68 and $30 \%$ of mice developed tumors, respectively (Table I). Furthermore, the appearance of SCK.18 tumors was delayed compared with SCK tumors, and SCK.18C tumors developed more slowly than SCK.18A tumors (Fig. 1 and Table I). SCID mice injected with SCK.18A cells uniformly developed tumors but their appearance was delayed compared with SCK tumors (Fig. $1 B$ ). Thus, T and/or B cells were required for rejection of SCK.18A cells, but cells present in SCID mice were able to delay tumor formation.

When $\mathrm{A} / \mathrm{J}$ mice were given anti-IFN- $\gamma$ antibody, five out of five mice given SCK.18C cells rapidly developed tumors (Table II). Since tumors only developed in one of five mice given no antibody, and two of five mice given control antibody, IFN- $\gamma$ is required both for rejection and delay in tumor development of SCK.18 cells. Interestingly, the mIL-18 antitumor effect did not require endogenous mIL-12 because only two of five mice given anti-mIL-12 antibody developed tumors which were delayed in their appearance.

Histology of SCK.12 and SCK.18 tumors. Histologic examination of SCK.12 and SCK.18 tumors revealed that, unlike SCK tumors that show only a few scattered, individual cells undergoing cell death (Fig. 2, $A$ and $B$; arrows in $B$ ), both mIL-12 and mIL-18-expressing tumors have significant areas of necrosis by day four (Fig. 2, $C$ and $D$, and $E$ and $F$, respectively; asterisks indicate necrosis). SCK.18 tumors demonstrate focally necrotic areas by day 4 (Fig. 2 E, asterisks), while SCK.12 tumors have significantly more extensive and complete necrosis (Fig. 2 C, asterisk) with only scattered areas of viable tumor cells (one can be seen in the upper left corner of Fig. 2 C). Both SCK.12 and SCK.18 cells induce a significant inflammatory response within areas of necrosis consisting primarily of polymorphonuclear cells (Fig. 2, $D$ and $F$, arrows) that is not seen in SCK tumors (Fig. $2 A$ ). Together, these observations indicate that mIL-18 and mIL-12 induce significantly more inflammation than SCK tumors alone and that mechanisms inducing tumor cell death occur more rapidly in SCK.12 and SCK.18 tumors than in the wild-type SCK tumors.

Effects of SCK.12 and SCK.18 cells on distant SCK tumors. The striking absence of tumor formation by SCK.12C cells led us to test whether they could induce rejection of SCK cells. We injected $\mathrm{A} / \mathrm{J}$ mice with $2.5 \times 10^{4} \mathrm{SCK} .12 \mathrm{C}$ cells in the right flank and $2.5 \times 10^{4} \mathrm{SCK}$ cells either in the same location (by mixing the two cell types in vitro before injection) or in the left flank. In mice coinjected with SCK and SCK.12C cells at the same site, only $30 \%$ developed tumors, and these were delayed in appearance (Table III and Fig. $3 A$ ). When SCK cells were injected at a distance from the SCK.12C cells, $90 \%$ of mice developed SCK tumors which were delayed in their appearance. Similar experiments were performed with SCK.18A and SCK.18C cells. As expected from the weak antitumor activity of SCK.18A cells alone, protection from SCK tumors was indeed poor (Table III and Fig. $3 \mathrm{~B}$ ). All mice coinjected with SCK mixed with SCK.18A cells developed tumors (which were delayed in appearance); all mice injected with SCK.18A and SCK cells in opposite flanks developed SCK tumors with only a slight delay, and eight out of ten also developed SCK.18A tumors. Although SCK.18C cells secrete more mIL-18 and are less tumorigenic than SCK.18A cells, a coinjection experiment performed with SCK.18C cells produced similar results (data not shown). These data indicate that the protection conferred by SCK.12C cells has strong local effects but weak systemic effects against SCK cells.

Because of their ability to synergistically induce IFN- $\gamma$ by T cells in vitro (23), we asked whether mIL-12 and mIL-18 together might produce a synergistic antitumor response. We injected mice with a mixture of $2.5 \times 10^{4} \mathrm{SCK} .12 \mathrm{C}$ cells and $2.5 \times 10^{4}$ SCK. 18 A cells in the right flank and $2.5 \times 10^{4} \mathrm{SCK}$ cells in the left flank. Although neither SCK.12C nor SCK.18A cells alone provided mice with much protection, the two cell types together protected the majority of mice from distant SCK tumors that were markedly delayed when they developed (Fig. $3 C$ and Table III). The difference in survival between mice receiving SCK.12C plus SCK.18A cells (70\%) and mice receiving either cell type alone (10\% for SCK.12C, $0 \%$ 

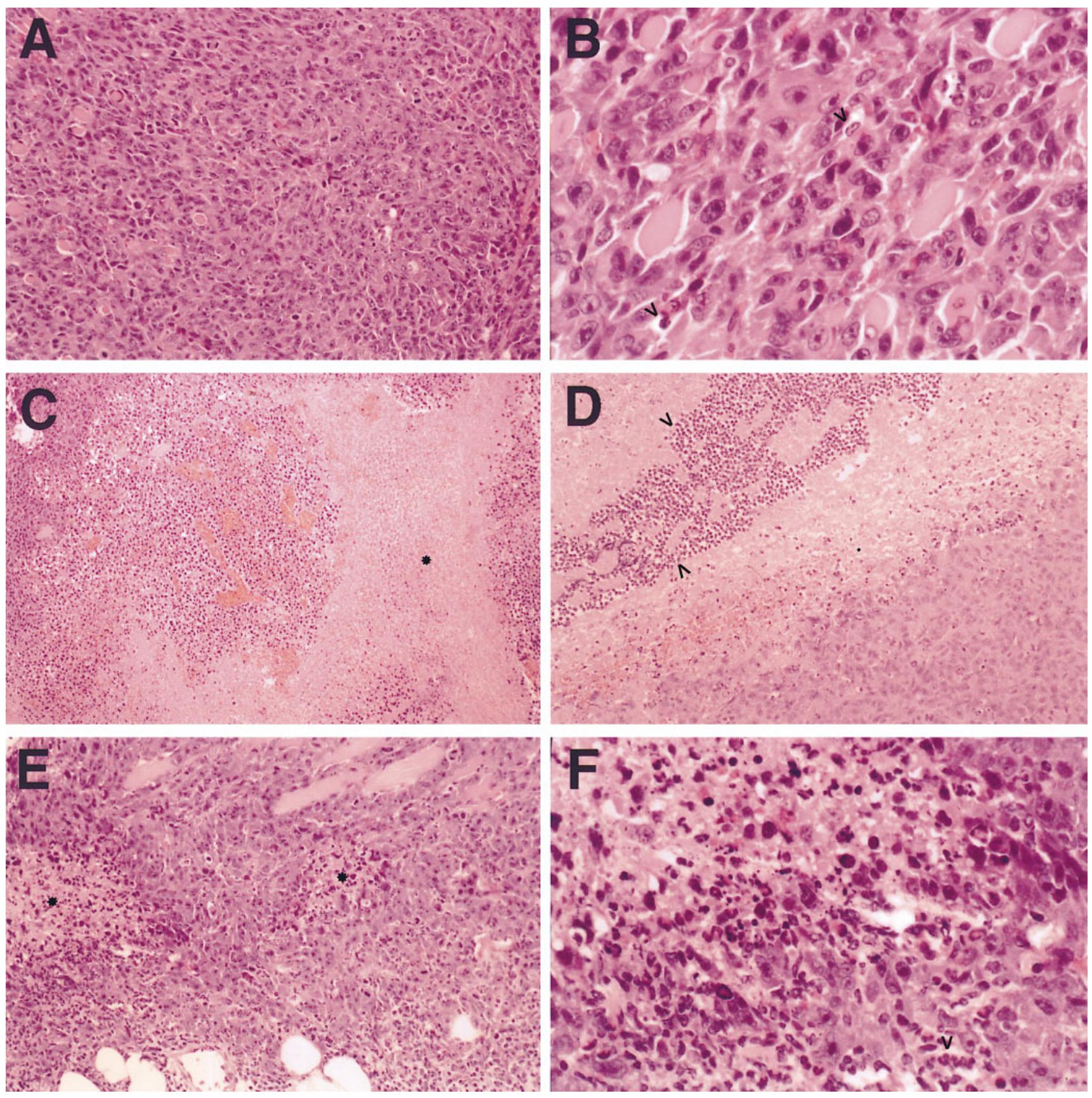

Figure 2. Histological analysis of SCK, SCK.12C, and SCK.18A tumors. A/J mice were injected with $2.5 \times 10^{4}$ SCK, SCK.18A, or $10^{6}$ SCK.12C cells. $4 \mathrm{~d}$ after tumors became palpable, they were removed, fixed in $10 \%$ buffered formalin and embedded in paraffin. Paraffin sections were stained with hematoxylin/eosin. The panels are representative photomicrographs of each of these tumors at two magnifications. $(A)$ SCK tumor at $\times 100$; no areas of coagulative necrosis are seen. $(B)$ SCK tumor at $\times 500$; nuclear fragments of individual tumor cells undergoing apoptotic cell death (arrowheads) are scattered throughout the tumor. (C) SCK.12C tumor at $\times 40$; extensive coagulative necrosis (asterisk) with residual ghost outlines of necrotic tumor cells. Viable tumor is seen in the upper left corner, while tumor cells in the center are undergoing necrosis. $(D)$ SCK.12C tumor at $\times 100$; neutrophilic infiltration of a zone of coagulative necrosis resulting in focal microabscesses (arrowheads). (E) SCK.18A tumor at $\times 100$; small foci of coagulative necrosis (asterisks) are scattered throughout the tumor but are less extensive than in SCK.12C tumors of the same age. $(F)$ SCK.18A tumor at $\times 300$; neutrophils (arrowhead) infiltrate the tumor at the periphery of necrotic foci.

for SCK.18A) is highly significant $(P<.005)$ and indicates a synergistic or cooperative induction of systemic tumor protection by the two secreted cytokines. Improved protection by SCK.12C plus SCK.18A cells was not due to enhanced cytokine secretion by the engineered cells because IL-18 from
SCK.18A conditioned medium did not enhance SCK.12C cell secretion of IL-12, and IL-12 from SCK.12C conditioned medium did not enhance SCK.18A cell secretion of IL-18. The improved protection was dependent on endogenously produced IFN- $\gamma$, shown by treating mice with anti-IFN- $\gamma$ anti- 
Table III. Antitumor Effects of SCK.12C, SCK 18A, and SCK.12C plus SCK.18A Cells against SCK Tumors

\begin{tabular}{llccc}
\hline \multicolumn{2}{c}{ Tumor cells injected* } & & \\
\cline { 1 - 2 } Right flank & Left flank & $\begin{array}{c}\text { Mice with } \\
\text { tumors }^{\ddagger}\end{array}$ & Time to tumor \\
\hline SCK & SCK & $10 / 10(100 \%)$ & $8.5 \pm 2.3$ \\
SCK.12C & None & $0 / 10(0 \%)$ & - \\
SCK.12C + SCK & None & $3 / 10(30 \%)$ & $15.0 \pm 1.5$ \\
SCK.12C & SCK & $9 / 10(90 \%)$ & $14.0 \pm 1.6$ \\
SCK.18A & None & $7 / 10(70 \%)$ & $13.0 \pm 3.1$ \\
SCK.18A + SCK & None & $10 / 10(100 \%)$ & $14.5 \pm 2.7$ \\
SCK.18A & SCK & $10 / 10(100 \%)$ & $9.0 \pm 1.6$ \\
SCK.12C + SCK.18A & None & $0 / 5(0 \%)$ & - \\
SCK.12C + SCK.18A & SCK & $3 / 10(30 \%)$ & $19.0 \pm 5.1$ \\
& & & \\
\hline
\end{tabular}

* Tumor cells of the indicated type were injected subcutaneously in the indicated flank. When two cell lines were injected into the right flank, they were mixed in vitro before injection. The dose of cells was $2.5 \times$ $10^{4}$ cells per cell line per mouse. These results were compiled from two separate experiments, with consistent results. ${ }^{*}$ Mice with tumors: indicated as the number of mice developing tumors/the number of mice in the cohort. The percentage of mice developing tumors is indicated in parentheses. ${ }^{\S}$ Time to tumor is the number of days after the animal was injected with cells before the tumor became detectable. These data are expressed as the median number of days for all mice in the group that developed tumors \pm SD.

body which abrogated protection. In this particular antibody ablation experiment, two out of five mice given no antibody and three out of five mice given control antibody developed tumors with the characteristic delay in tumor appearance (Table IV).

The systemic protection afforded by the combination of SCK.12C plus SCK.18A cells led us to test whether it could protect against previously established SCK tumors. Mice were

Table IV. Effect of IFN- $\gamma$ or IL-12 Neutralization on the Antitumor Response Induced by SCK.12 and SCK.18 Cells

\begin{tabular}{cclccr}
\hline \multicolumn{2}{c}{ Tumor cells injected* } & & & \\
\cline { 1 - 2 } Right flank & Left flank & & Antibody & $\begin{array}{c}\text { Mice with } \\
\text { tumors }\end{array}$ & Time to tumor \\
\hline SCK.12C + SCK.18A & SCK & None & $2 / 5$ & $22.0 \pm 4.2$ \\
SCK.12C + SCK.18A & SCK & NRA & $3 / 5$ & $22.0 \pm 5.5$ \\
SCK.12C + SCK.18A & SCK & $\alpha$-IFN- $\gamma$ & $5 / 5$ & $8.0 \pm 1.1$ \\
& & & &
\end{tabular}

*Tumor cells of the indicated type were injected subcutaneously in the indicated flank. When two cell lines were injected into the right flank, they were mixed in vitro before injection. The dose of cells is $2.5 \times 10^{4}$ cells per cell line per mouse. ${ }^{\ddagger}$ Antibodies of the indicated type were injected on days $-1,1,3$, and 6 , with respect to tumor cell injections (day 0 ). $N R A$, normal rat antibody. ${ }^{\S}$ Mice with tumors: indicated as the number of mice developing tumors/the number of mice in the cohort. "Time to tumor: the number of days after the animal was injected with cells before the tumor became detectable. These data are expressed as the median number of days for all mice in the group that developed tumors \pm SD. injected with SCK cells in the left flank on day 0 and with SCK.12C plus SCK.18A cells in the right flank on day 3. Whereas neither SCK.12C nor SCK.18A cells alone induced rejection of these established SCK tumors (SCK.12C cells did delay their growth), the combination induced rejection in 3 out of 10 mice. This showed that the combination of secreted mIL12 and mIL-18 could control established SCK tumors which is remarkable because SCK tumors are very aggressive. Their rapid clinical course offers a very narrow window of therapeutic opportunity and, previously, we were unable to cure A/J mice of SCK tumors established $3 \mathrm{~d}$ earlier with other maneuvers (11).

Antitumor immunity induced by SCK.12 and SCK.18 cells. SCK.12 plus SCK.18 cells could protect against SCK tumors by inducing immune responses against SCK antigens. We assessed the presence of antitumor immunity by rechallenging surviving mice with $10^{5}$ wild-type SCK cells (four times the usual challenge dose) $8-9$ wk after their initial encounter with the engineered SCK cells (Table V). Of 16 mice that survived an initial challenge of $2.5 \times 10^{4}$ SCK.12C cells, 7 (44\%) rejected this rechallenge, indicating that less than half of the survivors had protective immunity. Of eight survivors of $2.5 \times 10^{4}$ SCK.18A cells, four $(50 \%)$ rejected their rechallenge, and of 13 survivors of $2.5 \times 10^{4}$ SCK.12C plus SCK.18A cells, 6 $(46 \%)$ rejected their rechallenge. Thus, approximately half or less of the mice surviving any of these challenges were protected 2 mo later. This is low considering the virtual absence of SCK.12C tumorigenicity and the excellent systemic protection afforded by SCK.12C plus SCK.18A cells. We considered the possible explanation that protective immunity was present initially but had waned by 2 mo. To test this, mice that were tumor-free after injection of SCK.12C or SCK.12C plus SCK.18A cells were rechallenged in the opposite flank with $10^{5}$ SCK cells 2 or 4 wk later. At $2 \mathrm{wk}$, one out of eight mice given SCK.12C cells alone and four out of eight mice given SCK.12C plus SCK.18A cells survived their rechallenge, while at $4 \mathrm{wk}$, four out of eight mice given SCK.12C cells alone were protected (Table V). Clearly, mice given SCK.12C cells with or without SCK.18A cells were not better protected at 2 wk than at 2 mo. We also examined the spleens of mice for evidence of SCK-specific cytolytic activity but found that splenocytes from

Table V. Immunity Against SCK Cells in Mice Surviving SCK.12 and SCK.18 Cells

\begin{tabular}{lccc}
\hline $\begin{array}{c}\text { Mice surviving injected } \\
\text { tumor cells* }\end{array}$ & $\begin{array}{c}\text { Day of } \\
\text { rechallenge }\end{array}$ & $\begin{array}{c}\text { Mice surviving } \\
\text { rechallenge }\end{array}$ & Survival \\
\hline SCK.12C & 14 & $1 / 8$ & $12 \%$ \\
& 28 & $4 / 8$ & $50 \%$ \\
SCK.18A & 60 & $7 / 16$ & $44 \%$ \\
SCK.12C + SCK.18A & 60 & $4 / 8$ & $50 \%$ \\
& 14 & $4 / 8$ & $50 \%$ \\
& 60 & $6 / 13$ & $46 \%$ \\
\hline
\end{tabular}

* Mice survived injections of the tumor cell types indicated. The dose of cells was $2.5 \times 10^{4}$ cells per cell line per mouse. ${ }^{\ddagger}$ Survivors were rechallenged with $10^{5} \mathrm{SCK}$ cells on the indicated number of days after the initial injections of cells (day 0 ). ${ }^{8}$ Mice with tumors is the number of mice developing tumors/the number of survivors rechallenged in the cohort. "Survival: percentage of rechallenged mice in the group that rejected the rechallenge dose of SCK cells. 


\section{A SCK.12C cells}

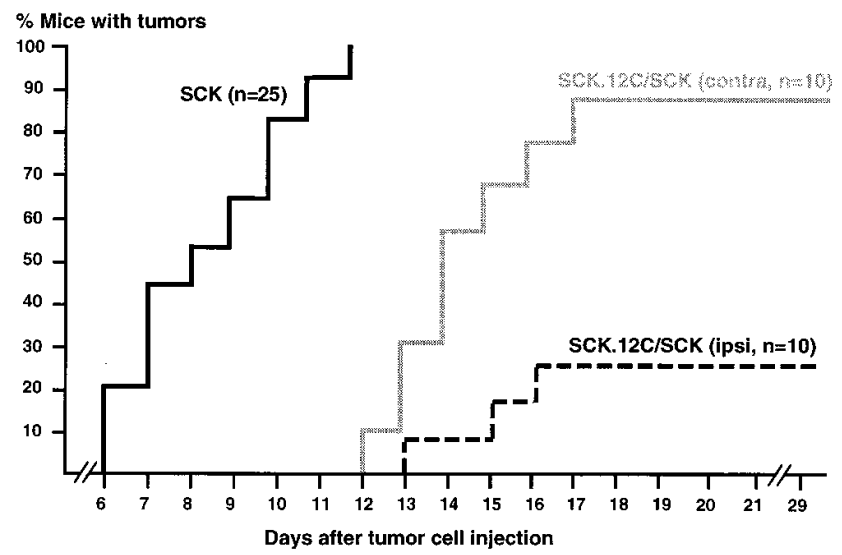

B SCK.18A cells

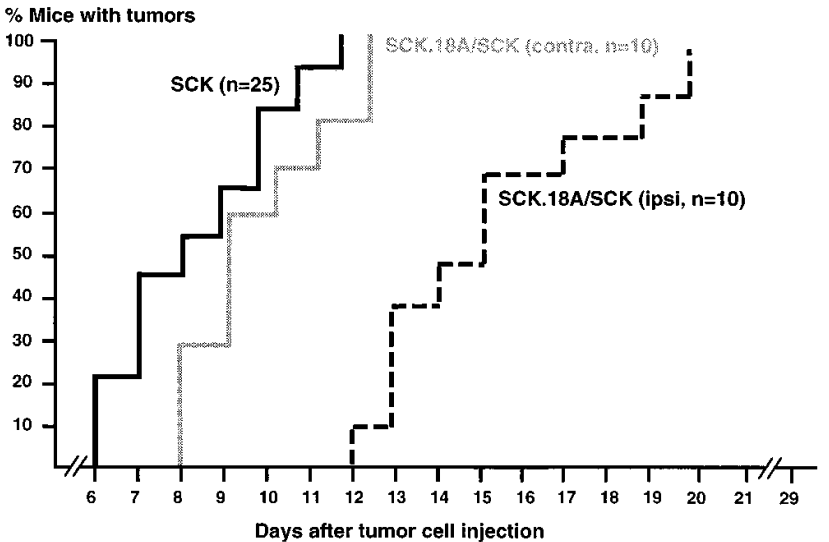

\section{SCK.12C+SCK.18A cells}

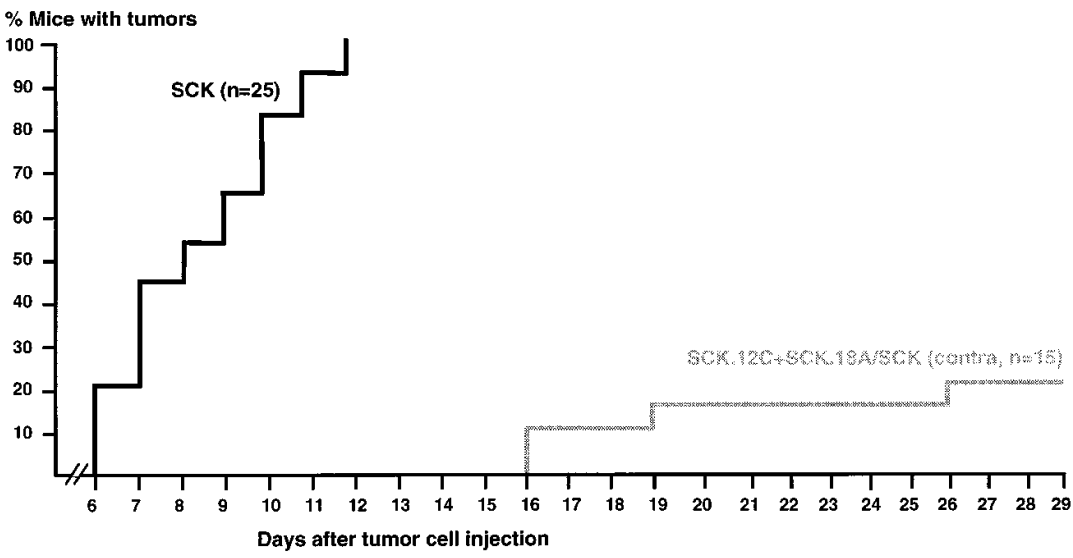

\section{SCK.12C+SCK.18A cells (with Sa-1 cells)}

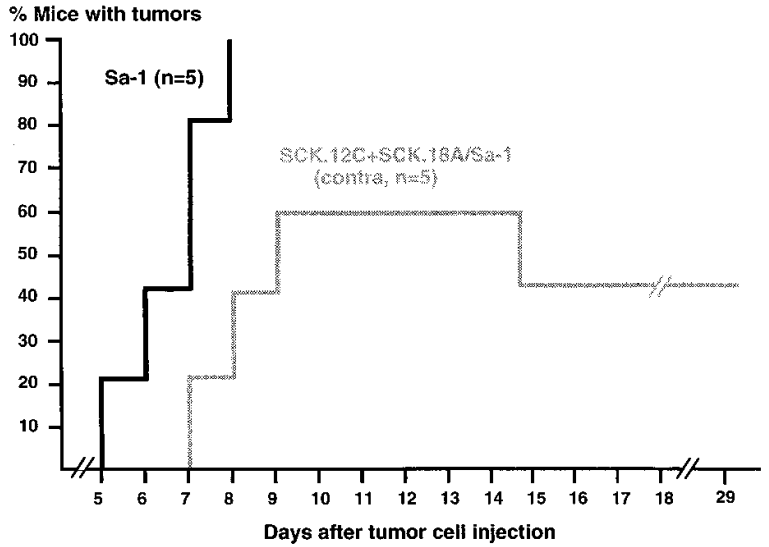

Figure 3. SCK tumor development in mice receiving SCK.12C, SCK.18A, or SCK.12C plus SCK.18A cells. In $A, B$, and $C, \mathrm{~A} / \mathrm{J}$ mice were injected with $2.5 \times 10^{4} \mathrm{SCK}$ cells in one flank. $(A)$ Groups of mice received SCK cells alone (solid black lines), SCK and SCK.12C cells injected in the same flank (ipsi; dashed black lines), or SCK and SCK.12C cells injected in opposite flanks (contra; gray lines). Similar experiments using SCK.18A cells instead of SCK.12C cells are shown in $B$. (C) Mice received SCK cells alone (solid black lines) or SCK cells and an equal mixture of SCK.12C plus SCK.18A cells in opposite flanks (gray lines). (D) Mice were injected with $10^{6} \mathrm{Sa}-1$ cells alone (solid black lines) or Sa-1 cells and an equal mixture of SCK.12C plus SCK.18A cells in opposite flanks (gray lines). All cells were injected on day 0 , and mice were monitored daily for tumor development. 

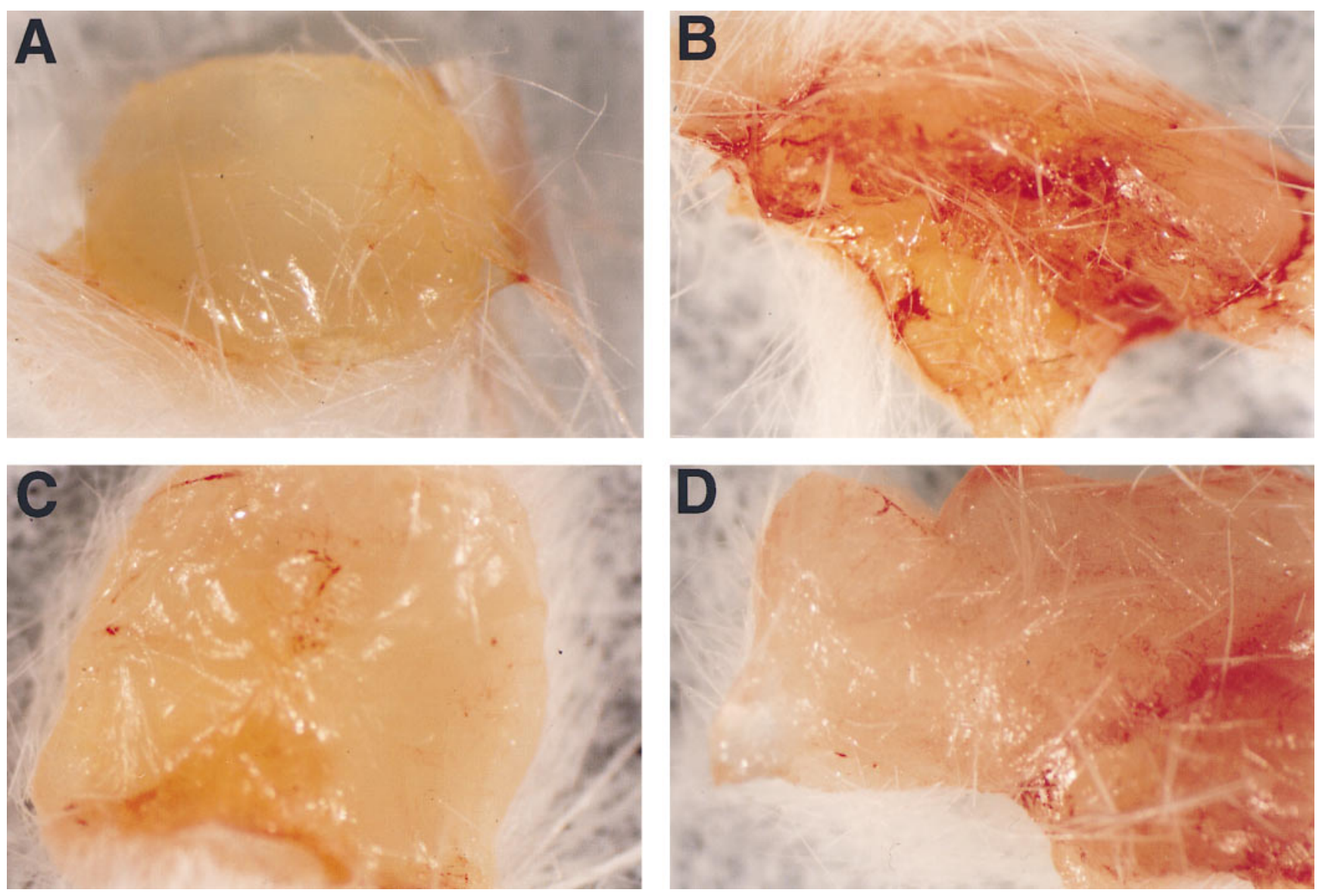

Figure 4. Matrigel implants harvested from A/J mice. Matrigel $(0.5 \mathrm{ml})$ was injected subcutaneously on day 0 in the midline of the abdomen of $\mathrm{A} / \mathrm{J}$ mice. After $4 \mathrm{~d}$, the Matrigel implants were harvested and photographed using a dissecting microscope. The Matrigel contained no cells $(A)$, $10^{5}$ SCK cells $(B), 10^{5}$ SCK.12C cells $(C)$, or $10^{5}$ SCK.18A cells $(D)$.

A/J mice injected with SCK.12C, SCK.18A or SCK.12C plus SCK.18A cells $14 \mathrm{~d}$ earlier had no significant CTL activity.

Inhibition of angiogenesis mediated by SCK.12 and SCK.18 cells. The rechallenge data indicated that protective immunity did not develop in half of mice given SCK.12C or SCK.12C plus SCK.18A cells. Antitumor immunity therefore could not account for the observed lack of SCK.12C tumorigenicity and was unlikely, by itself, to underlie the systemic protection afforded by coinjected SCK.12C plus SCK.18A cells. That SCK.12C cells protected well against local but not distant SCK tumorigenesis reinforced this conclusion. Given the observation that very large inocula of SCK.12C cells (40 times the usual number of cells injected) formed only small tumors that spontaneously regressed and knowing that administration of rmIL-12 can inhibit angiogenesis $(17,18)$, we hypothesized that inhibition of tumor angiogenesis might explain the behavior and effects of SCK.12C and SCK.18A cells. To test this hypothesis, we used Matrigel (Collaborative Biomedical Products) implants as an in vivo assay for tumor angiogenesis (31) and quantitated vascularization by measuring hemoglobin content (32). Matrigel $(0.5 \mathrm{ml})$ implants without additives were pale and unvascularized $4 \mathrm{~d}$ after implantation (Fig. $4 \mathrm{~A}$ and Fig. $5 \mathrm{~A}$ ). Inclusion of $10 \mathrm{ng}$ rbFGF or $10^{5} \mathrm{SCK}$ cells in the implant provides an angiogenic stimulus that made it visibly vas- cularized (Fig. $4 B$ and Fig. $5 A$, SCK cells). SCK.12C and SCK.18A cells in Matrigel implants (Fig. 4, $C$ and $D$, respectively) do not induce nearly the same degree of vascularization as SCK cells (Fig. $5 A$ ).

SCK.12C and SCK.18A cells induced much less vascularization than SCK cells (Fig. $5 A$ ). This could result from decreased production of angiogenic factors by the engineered tumor cells and/or from the presence of an angiogenesis inhibitor. An inhibitor is present at the least, inasmuch as Matrigel implants containing SCK.12C cells or an equal mixture of SCK and SCK.12C cells were equally poorly hemoglobinized (data not shown). That the inhibitor is IFN- $\gamma$ or is stimulated by IFN- $\gamma$ is shown by the ability of anti-IFN- $\gamma$ antibody treatment to restore the ability of SCK.12C and SCK.18A cells to stimulate angiogenesis to the levels stimulated by wild-type SCK cells (Fig. $5 A$ ). Inhibition of tumor angiogenesis by SCK.12C cells may explain why these cells are essentially nontumorigenic and can effectively prevent tumorigenesis by coinjected SCK cells. Both SCK.12C and SCK.18A cells reduced angiogenesis of distant Matrigel implants containing SCK cells, but SCK.12C plus SCK.18A cells together inhibited systemic angiogenesis more effectively than either cell type alone (Fig. 5 B). This cooperative effect might contribute to or be responsible for the better protection against distant SCK tumors 

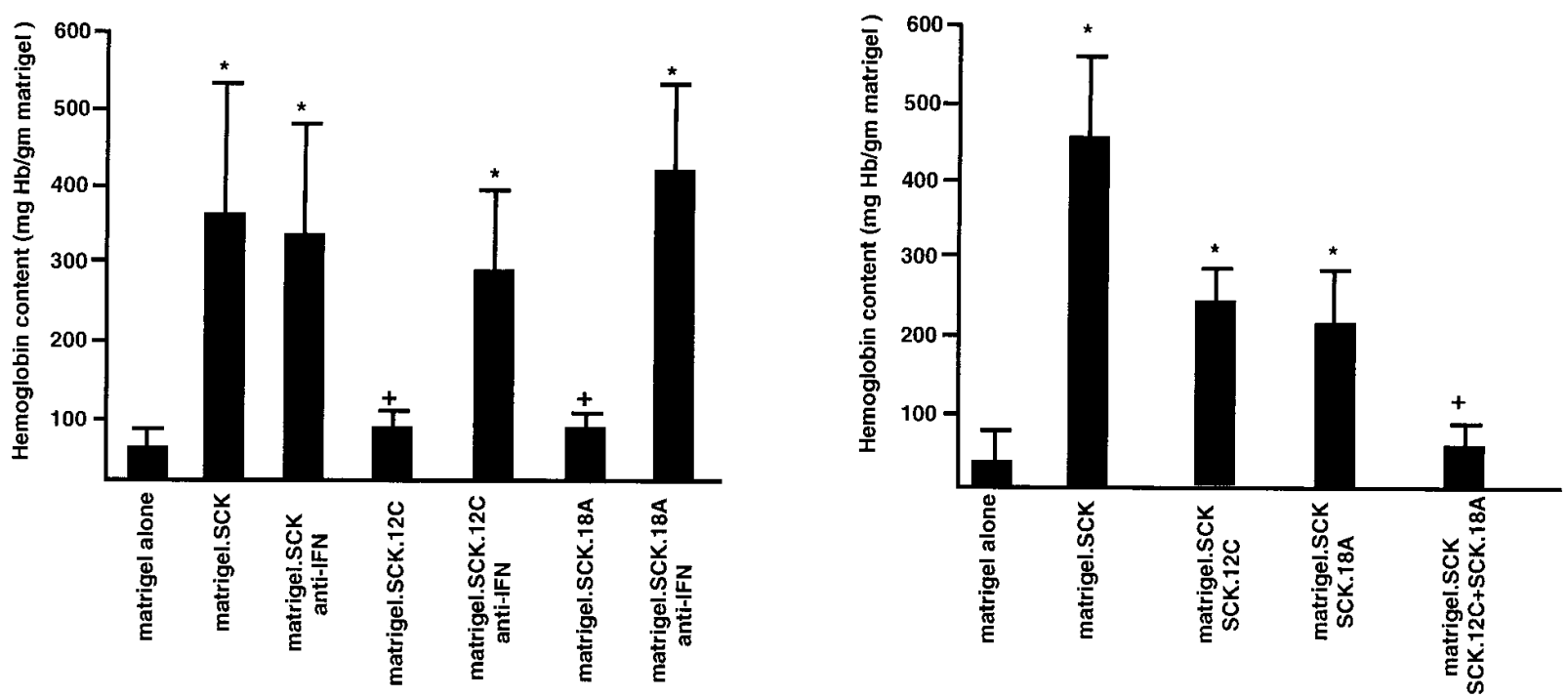

C anti-IFN- $\gamma$ treatment with Matrigel

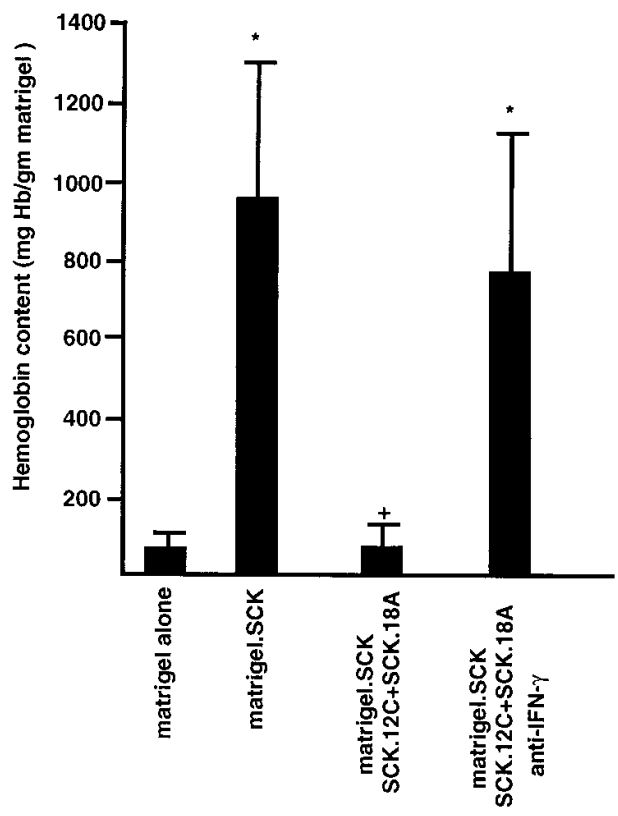

D Matrigel containing bFGF or SCK or Sa-1 cells

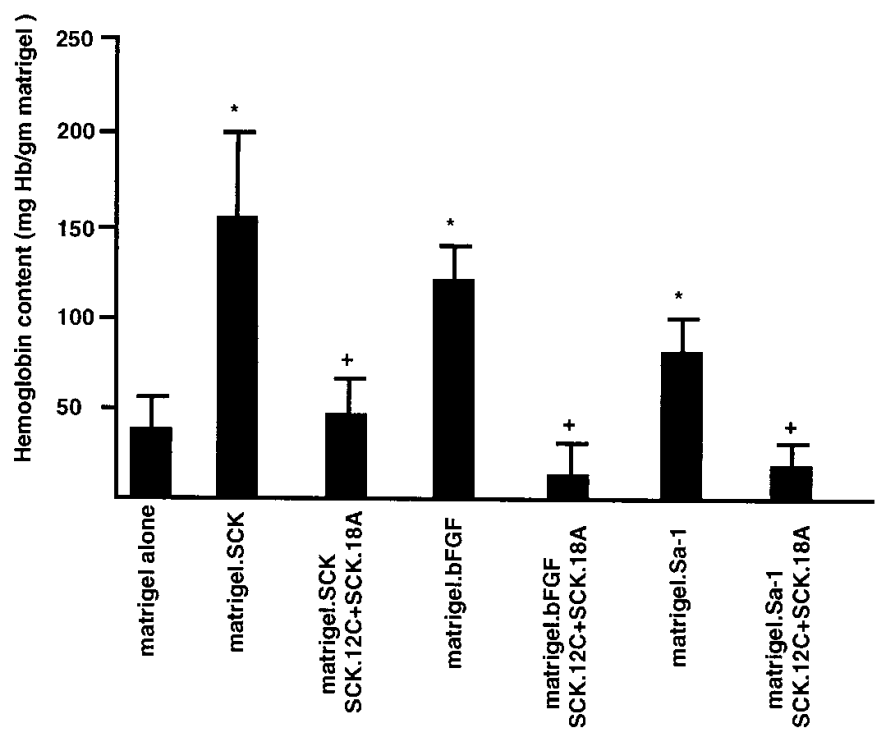

Figure 5. Vascularization of Matrigel implants. Mice were injected subcutaneously with $0.5 \mathrm{ml}$ Matrigel either alone or mixed with $10^{5}$ tumor cells. $6 \mathrm{~d}$ later, the Matrigel implants were harvested and their hemoglobin content assayed by the Drabkin method (see Methods). $(A)$ The Matrigel contained SCK, SCK.12C or SCK.18A cells, as indicated. Half of the Matrigel-bearing mice were given neutralizing anti-IFN- $\gamma$ antibody. $(B)$ The Matrigel contained SCK cells. SCK.12C, SCK.18A or both types of cells were injected at a distant site. $(C)$ The Matrigel contained SCK cells. Some mice were injected with SCK.12C plus SCK.18A cells at a distant site, and some of these were treated with anti-IFN- $\gamma$ mAb on days $-1,1$, and 3. $(D)$ The Matrigel contained SCK $\left(10^{5}\right)$ or Sa-1 $\left(10^{6}\right)$ cells or $10 \mathrm{ng}$ rb-FGF. Half of the mice in each group were injected with SCK.12C plus SCK.18A cells at a distant site. $\left(*\right.$ and $\left.{ }^{+}\right)$Indicate groups with significantly different hemoglobin content $(P<0.05)$. Each group contained three mice whose implants were assayed separately. Bars indicate the standard deviation of the hemoglobin measurements.

afforded by the combination of mIL-12- and mIL-18-secreting cells.

Antibody neutralization of IFN- $\gamma$ abrogated systemic angiogenesis inhibition by SCK.12C plus SCK.18A cells (Fig. 5
$C)$ which indicated that their effect was mediated by IFN- $\gamma$. This suggested that the antiangiogenic effect of SCK.12C plus SCK.18A cells is not tumor cell or angiogenic factor specific which was confirmed when they were shown to effectively in- 
hibit Matrigel angiogenesis induced by rb-FGF or Sa-1 sarcoma cells (Fig. $5 \mathrm{D}$ ). Thus, the antiangiogenic effects of tumor cell-secreted mIL-12 and mIL-18 are not limited to angiogenesis induced by homologous tumor cells and are active against different stimulants of neovascularization. That this contributes to the overall antitumor effect of SCK.12C plus SCK.18A cells was shown by the fact that these cells could consistently retard and sometimes prevent tumor formation by distant $\mathrm{Sa}-1$ cells. In one experiment (Fig. $3 D$ ), all five mice given only Sa-1 cells developed progressive tumors, whereas two of five mice that were given SCK.12C plus SCK.18A cells and Sa-1 cells in opposite flanks did not develop Sa-1 tumors, and one mouse that developed an Sa-1 tumor experienced complete tumor regression. In previous work (11), we showed that protective immunity to SCK cells and antigens does not confer protection against Sa-1 tumors indicating that Sa-1 tumor rejection in these mice cannot be due to development of anti-SCK immunity.

\section{Discussion}

The studies presented here examine the antitumor responses induced by tumor cells engineered to express either mIL-12 or mIL-18. Using SCK murine mammary carcinoma cells as the tumor model, both SCK.12 and SCK.18 cells exhibited a reduction in tumorigenicity that correlated with the level of cytokine secreted. The effect is most striking in the case of SCK cells secreting mIL-12 where those secreting the most, SCK.12C cells, failed to form progressive tumors even when 40 times the usual tumorigenic dose of SCK cells was injected into syngeneic mice. These cells create an environment unfavorable for progressive tumor growth as shown by their ability to prevent tumor formation by colocalized SCK cells. This effect is more local than systemic, however, and these cells only weakly prevent distant SCK cells from forming progressive tumors. Poor systemic protection speaks against antitumor immunity being the primary mechanism responsible for rejection of SCK.12C tumors, a conclusion that is additionally supported by the fact that only half the mice injected with SCK.12C cells develop protective immunity which takes more than 2 wk to be fully manifest. A better candidate for the primary mechanism underlying SCK.12C tumor rejection is inhibition of tumor angiogenesis. This is supported by the fact that angiogenesis is necessary and limiting for tumor growth (33, 34 ), that SCK.12C cells are clearly antiangiogenic and that the antitumor effects of SCK.12C cells require IFN- $\gamma$ which is known to mediate the antiangiogenic effects of mIL-12 $(17,18)$. The major reason to question whether angiogenesis inhibition is responsible for the antitumor effect of secreted mIL-12 is the fact that IFN- $\gamma$ has other activities that may also promote tumor regression (14), such as inhibition of cell proliferation, direct toxic effect on cells in combination with TNF- $\alpha$ and induction of inducible nitric oxide synthase. Thus, angiogenesis inhibition is not the only IFN- $\gamma$ effect potentially responsible for SCK.12C antitumor effects.

The antitumor effects of SCK.18 cells were less striking than those of SCK.12C cells. Tumorigenesis by SCK.18 cells was reduced but not ablated, and these cells provided little if any protection against tumor formation by neighboring or distant SCK cells. However, because SCK cells expressing higher levels of mIL-18 were unavailable for study and may have produced greater effects, these results do not provide a compari- son of the intrinsic antitumor effectiveness of mIL-18 and mIL-12. mIL-18 clearly does not need mIL-12 for its antitumor effects, because mIL-12-neutralization does not diminish its effectiveness. Despite this, one would predict that these two cytokines activate many of the same antitumor mechanisms because both induce IFN- $\gamma$ production by lymphocytes, and SCK.18 cells, like SCK.12 cells, require IFN- $\gamma$ for their antitumor effects. This prediction was confirmed in the case of angiogenesis inhibition, since SCK.18A cells, like SCK.12C cells, induced markedly less Matrigel neovascularization than SCK cells, and both SCK.18A and SCK.12C cells inhibited angiogenesis induced by SCK cells. This similarity suggests that angiogenesis inhibition may account for some of the shared features of SCK.18 and SCK.12 tumorigenesis, such as the IFN- $\gamma$-dependent delay in tumor appearance. By the same reasoning, factors other than angiogenesis inhibition may account for the differences between SCK.12C and SCK.18A cells (e.g., incidence of progressive tumors and ability to inhibit tumor formation by colocalized SCK cells), although differences in their ability to inhibit angiogenesis that were undetectable by our assay may also be responsible.

Together, SCK.12 plus SCK.18 cells induce greater antitumor effects than either cell type alone. This is most evident in the ability of the two cell types to cooperate in protecting against SCK tumorigenesis systemically and in inducing a greater delay in SCK tumor appearance. Better protection and markedly retarded tumor growth are likely the result of more effective inhibition of angiogenesis by the combination of the two cell types. It is clear that SCK.12 plus SCK.18 cells do not cooperate to induce protective anti-SCK immunity in a greater percentage of mice. The mechanism(s) underlying cooperative induction of systemic protection and cooperative inhibition of angiogenesis by mIL-12 plus mIL-18 is unclear. Production of more IFN- $\gamma$ may be responsible, because these two cytokines can synergistically induce T cell production of IFN- $\gamma$ in vitro (23) and, together, can induce B cells to produce IFN- $\gamma$ in vitro (35). However, we have been unable to measure serum IFN- $\gamma$ levels in mice injected with SCK.12C cells, SCK.18A cells or both cell types, and therefore cannot document this effect in vivo. Whatever the mechanism, the ability of the two cytokines to provide far better tumor protection than either can alone suggests a potentially powerful way to use these cytokines therapeutically. Of course, clinical testing of IL-12 and IL-18 will use the recombinant proteins primarily, and it remains to be seen whether rIL-12 and rIL-18 induce antitumor effects cooperatively.

The development of protective immunity in half or less of the mice rejecting SCK.12C and/or SCK.18A cells indicates that mechanisms other than or in addition to antigen-specific immunity are responsible for their rejection. Others have also observed the absence of protective immunity in a significant percentage of survivors of mIL-12-secreting tumor cells (36). The importance of antigen-nonspecific antitumor mechanisms activated by mIL-12 and mIL-18 raises the question as to what it or these might be. The mechanism(s) is almost certainly dependent on IFN- $\gamma$, as shown by the abrogation of protective effects by IFN- $\gamma$ neutralization. Among IFN- $\gamma$-activated events with potential impact on tumorigenesis, inhibition of angiogenesis is the best candidate. Recombinant mIL-12 has been shown to have potent antiangiogenic activity (17-20), and we find that levels of mIL-12 and mIL-18 secreted by our engineered tumor cells have similar activity. Given the importance 
of angiogenesis for tumor growth, its inhibition is likely to be a crucial mechanism for their antitumor efficacy. It is also perhaps the only known IFN- $\gamma$-activated antitumor mechanism that is unlikely to be overwhelmed by dramatic increases in the size of the tumor cell inoculum (no progressive tumors resulted from SCK.12C inocula 40 times the usual size). The available evidence suggests the IFN- $\gamma$ produced in response to IL-12 induces the production of interferon-inducible protein 10 (IP-10) and monokine induced by $\gamma$-IFN (MIG) which result in angiogenesis inhibition and tumor necrosis $(18,37,38)$. mIL-18 probably also operates through this pathway to produce similar effects. We believe that angiogenesis inhibition by mIL-12 and mIL-18 is the major mechanism underlying their ability to delay SCK tumorigenesis and protect against SCK tumors, both of which are IFN- $\gamma$ dependent. This effect is not tumor or antigen specific, as shown by the fact that SCK.12 plus SCK.18 cells inhibit angiogenesis promoted by unrelated, syngeneic Sa-1 sarcoma cells and can consistently delay and occasionally prevent Sa-1 tumor development. However, angiogenesis inhibition may not be enough for ultimate protection from tumors. Perhaps the appropriate perspective on angiogenesis inhibition during mIL-12-induced tumor regression is provided by studies of other angiogenesis inhibitors, such as angiostatin (39) and endostatin (40), which show that the most effective of these compounds induce shrinkage of large tumors and prevent growth of small tumors but do not eradicate residual tumor cells. If stasis of small tumor cell nests is the therapeutic limit of angiogenesis inhibitors, the curing of SCK tumors by mIL-12 and mIL-18 is evidence that these cytokines invoke additional tumoricidal effects.

\section{Acknowledgments}

We wish to thank Muhammed Tauseef Rehman for excellent technical assistance, Scott Wright for animal care assistance, Ning-Sun Yang for the gift of the pWRG vector, Sydney Pestka for the gift of the pEF2 vector and Susan Ostrand-Rosenberg for the gift of Sa-1 cells.

W.M.F. Lee, K.E. Salhany, G. Trinchieri, and M. Wysocka are supported by awards from the National Institutes of Health. C.M. Coughlin is supported by the NIH M.S.T.P. grant. H. Kurzawa is supported by a US Army predoctoral training grant. A.E. Chang is supported by grants from the NIH and the ACS Faculty Research Award. C.A. Hunter is a Burroughs-Wellcome assistant professor of molecular parasitology. J.C. Fox is supported by grants from the $\mathrm{NIH}$, the American Heart Association, and the University of Pennsylvania Research Foundation.

\section{References}

1. Martinotti, A., A. Stoppacciaro, M. Vagliani, C. Melani, F. Spreafico, M. Wysocka, G. Parmiani, G. Trinchieri, and M. Colombo. 1995. CD4 T cells inhibit in vivo CD8-mediated immune response against a murine colon carcinoma transduced with IL-12 genes. Eur. J. Immunol. 25:137-146.

2. Colombo, M.P., M. Vagliani, F. Spreafico, M. Parenza, C. Chiodoni, C. Melani, and A. Stoppacciaro. 1996. Amount of interleukin 12 available at the tumor site is critical for tumor regression. Cancer Res. 56:2531-2534.

3. Tahara, H., L. Zitvogel, W.J. Storkus, H.J. Zeh III, T.J. McKinney, H. Schreiber, U. Gubler, P.D. Robbins, and M.T. Lotze. 1995. Effective eradication of established murine tumors with IL-12 gene therapy using a polycistronic retroviral vector. J. Immunol. 154:6466-6474.

4. Tahara, H., H.J. Zeh III, W.J. Storkus, I. Pappo, S.C. Watkins, U. Gubler, S. Wolf, P.D. Robbins, and M.T. Lotze. 1994. Fibroblasts genetically engineered to secrete IL-12 can suppress tumor growth and induce anti-tumor immunity to a murine melanoma in vivo. Cancer Res. 54:182-189.

5. Trinchieri, G. 1995. Interleukin-12: a proinflammatory cytokine with immunoregulatory functions that bridge innate resistance and antigen-specific adaptive immunity. Annu. Rev. Immunol. 13:251-276.

6. Hsieh, C.-S., S.E. Macatonia, C.S. Tripp, S.F. Wolf, A. O'Garra, and K.M. Murphy. 1993. Development of TH1 CD4 ${ }^{+}$T cells through IL-12 produced by Listeria-induced macrophages. Science. 260:547-550.

7. Yu, W.G., N. Yamamoto, H. Takenaka, J. Mu, X.G. Tai, J.P. Zou, M. Ogaa, T. Tsutsui, S. Herrmann, H. Fujiwara, and T. Hamoaka. 1996. Molecular mechanisms underlying IFN-gamma mediated growth inhibition induced during tumor immunotherapy with IL-12. Int. Immunol. 8:855-865.

8. Tsung, K., J.B. Meko, G.R. Peplinski, Y.L. Tsung, and J.A. Norton. 1997. IL-12 induces TH1-directed antitumor response. J. Immunol. 158:3359-3365.

9. Bloom, E.T., and J.A. Horvath. 1994. Cellular and molecular mechanisms of the IL-12-induced increase in allospecific murine cytolytic $\mathrm{T}$ cell activity. J. Immunol. 152:4242-4254.

10. Nastala, C.L., H.D. Edington, T.G. McKinney, H. Tahara, M.A. Nalesnik, M.J. Brunda, M.K. Gately, S.F. Wolf, R.D. Schreiber, W.J. Storkus, and M.T. Lotze. 1994. Recombinant IL-12 administration induces tumor regression in association with IFN- $\gamma$ production. J. Immunol. 153:1697-1706.

11. Coughlin, C.M., M. Wysocka, H.L. Kurzawa, W.M.F. Lee, G. Trinchieri, and S.L. Eck. 1995. B7-1 and interleukin-12 synergistically induce effective antitumor immunity. Cancer Res. 55:4980-4987.

12. Coughlin, C.M., M. Wysocka, G.T. Trinchieri, and W.M.F. Lee. 1997. The effect of interleukin 12 desensitization on the antitumor efficacy of interleukin 12. Cancer Res. 57:2460-2467.

13. Car, B.D., V.M. Eng, B. Schnyder, M. LeHir, A.N. Shakov, G. Woerly, S. Huang, M. Aguet, T.D. Anderson, and B. Ryffel. 1995. Role of IFN- $\gamma$ in interleukin 12-induced pathology in mice. Am. J. Pathol. 147:1693-1707.

14. Boehm, U., T. Klamp, M. Groot, and J.C. Howard. 1997. Cellular responses to interferon-gamma. Annu. Rev. Immunol. 15:749-795.

15. Revel, M., and J. Chebath. 1986. Interferon-activated genes. Trends Biochem. Sci. 11:166-170.

16. Xie, Q.W., R. Whisnant, and C. Nathan. 1993. Promoter of the mouse gene encoding calcium-independent nitric oxide synthase confers inducibility by interferon gamma and bacterial lipopolysaccharide. J. Exp. Med. 177:17791784 .

17. Voest, E.E., B.M. Kenyon, M.S. O'Reilly, G. Truitt, R.J. D'Amato, and J. Folkman. 1995. Inhibition of angiogenesis in vivo by IL-12. J. Natl. Cancer Inst. 87:581-586.

18. Sgadari, C., A.L. Angiolillo, and G. Tosato. 1996. Inhibition of angiogenesis by interleukin-12 is mediated by the interferon-inducible protein- 10 . Blood. 87:3877-3882.

19. Watanabe, M., K.L. McCormick, K. Volker, J.R. Ortaldo, J.M. Wigginton, M.J. Brunda, R.H. Wiltrout, and W.E. Fogler. 1997. Regulation of local host-mediated antitumor mechanisms by cytokines. Am. J. Pathol. 150:18691880 .

20. Majewski, S., M. Marczak, A. Szmurlo, S. Jablonska, and W. Bollag. 1996. Interleukin-12 inhibits angiogenesis induced by human tumor cell lines in vivo. J. Investig. Dermatol. 106:1114-1118.

21. Ushio, S., M. Namba, T. Okura, K. Hattori, Y. Nukada, K. Akita, F. Tanabe, K. Konishi, M. Micallef, M. Fujii, et al. 1996. Cloning of the cDNA for human interferon-gamma-inducing factor (IGIF), expression in E. coli, and studies on the biologic activities of the protein. J. Immunol. 156:4274-4279.

22. Okamura, H., H. Tsutsui, T. Komatsu, M. Yutsudo, A. Hakura, T. Tanimoto, K. Torigoe, T. Okura, Y. Nukada, K. Hattori, et al. 1995. Cloning of a new cytokine that induces IFN-gamma production by T cells. Nature. 378:88-91.

23. Micallef, M.J., T. Ohtsuki, K. Kohno, F. Tanabe, S. Ushio, M. Namba, T. Tanimoto, K. Torigoe, M. Fujii, M. Ikeda, et al. 1996. Interferon-gamma inducing factor enhances Th1 cytokine production by stimulated human T cells: synergism with interleukin 12 for interferon gamma production. Eur. J. Immunol. 26:1647-1651.

24. Tsutsui, H., K. Nakanishi, K. Matsui, K. Higashino, H. Okamura, Y. Miyazawa, and K. Kaneda. 1996. Interferon- $\gamma$-inducing factor (IGIF) upregulates Fas-ligand-mediated cytotoxic activity of murine natural killer cell clones. J. Immunol. 157:3967-3973.

25. Micallef, M.J., K. Yoshida, S. Kawai, T. Hanaya, K. Kohno, S. Arai, T. Tanimoto, K. Torigoe, M. Fujii, M. Ikeda, and M. Kurimoto. 1997. In vivo antitumor effects of murine interferon-g-inducing factor/interleukin 18 in mice bearing syngeneic Meth A sarcoma malignant ascites. Cancer Immunol. Immunother. 43:361-367.

26. Song, C.W., M.S. Kang, J.G. Rhee, and S.H. Levitt. 1994. Vascular damage and delayed cell death in tumors after hyperthermia. Br. J. Cancer. 41:309-312.

27. Baskar, S., S. Ostrand-Rosenberg, N. Nabavi, L.M. Nadler, G.J. Freeman, and L.H. Glimcher. 1993. Constitutive expression of B7 restores immunogenicity of tumor cells expressing truncated major histocompatibility complex class II molecules. Proc. Natl. Acad. Sci. USA. 90:5687-5690.

28. Tan, J., C.A. Newton, J.Y. Djeu, D.E. Gutsch, A.E. Chang, N.S. Yang, T.W. Klein, and Y. Hua. 1996. Injection of complementary DNA encoding interleukin-12 inhibits tumor establishment at a distant site in a murine renal carcinoma model. Cancer Res. 56:3399-3403.

29. Abrams, J.S., M.G. Roncarolo, H. Yssel, G.J. Andersson, and J.E. Silver. 1992. Strategies of anti-cytokine monoclonal antibody development: immunoassay of interleukin-10 and interleukin-5 in clinical samples. Immunol. Rev. 127:5-24. 
30. Wysocka, M., M. Kubin, L.Q. Vieira, L. Ozmen, G. Garotta, P. Scott, and G. Trinchieri. 1995. Interleukin-12 is required for interferon-g production and lethality in lipopolysaccharide-induced shock in mice. Eur. J. Immunol. 25: 672-676

31. Kleinman, H.K., M.L. McGarvey, L.A. Liotta, P.G. Robey, K. Tryggvason, and G.R. Martin. 1982. Isolation and characterization of type IV procollagen, laminin, and heparin sulfate proteoglycan from the EHS sarcoma. Biochemistry. 21:6188-6193.

32. Passaniti, A., R.M. Taylor, R. Pili, R. Guo, P.V. Long, J.A. Haney, D.S. Grant, and G.R. Martin. 1992. A simple quantitative method for assessing angiogenesis and antiangiogenic agents using reconstituted basement membrane, heparin and fibroblastic growth factor. Lab. Invest. 67:519-528.

33. Hanahan, D., and J. Folkman. 1996. Patterns and emerging mechanisms of the angiogenic switch during tumorigenesis. Cell. 86:353-364.

34. Folkman, J. 1997. Angiogenesis and angiogenesis inhibition: an overview. Exper. Suppl. (Basel). 79:1-8.

35. Yoshimoto, T., H. Okamura, Y. Tagawa, Y. Iwakura, and K. Nakanishi. 1997. Interleukin 18 together with interleukin 12 inhibits IgE production by induction of interferon-gamma from activated B cells. Proc. Natl. Acad. Sci. USA.
94:3948-3953

36. Cavallo, F., P. Signorelli, M. Giovarelli, P. Musiani, A. Modesti, M.J. Brunda, M.P. Colombo, and G. Forni. 1997. Antitumor efficacy of adenocarcinoma cells engineered to produce interleukin 12 (IL-12) or other cytokines compared with exogenous IL-12. J. Natl. Cancer Inst. 89:1049-1058.

37. Angiolillo, A.L., C. Sgdari, D.D. Taub, F. Liao, J.M. Farber, H.K. Kleinmann, G.H. Reaman, and G. Tosato. 1995. Human interferon inducible protein 10 is a potent inhibitor of angiogenesis in vivo. J. Exp. Med. 182:155-162.

38. Sgadari, C., J.M. Farber, A.L. Angiolillo, F. Liao, J. Teryua-Feldstein, P.R. Burd, L. Yao, G. Gupta, C. Kanegane, and G. Tosato. 1997. Mig, the monokine induced by interferon- $\gamma$, promotes tumor necrosis in vivo. Blood. 89 : 2635-2643.

39. O'Reilly, M.S., L. Holmgren, Y. Shing, C. Chen, R.A. Rosenthal, M. Moses, W.S. Lane, Y. Cao, E.H. Sage, and J. Folkman. 1994. Angiostatin: a novel angiogenesis inhibitor that mediates the suppression of metastases by a Lewis lung carcinoma. Cell. 79:315-328.

40. O'Reilly, M.S., T. Boehm, Y. Shing, N. Fukai, G. Vasios, W.S. Lane, E. Flynn, J.R. Birkhad, B.R. Olsen, and J. Folkman. 1997. Endostatin: an endogenous inhibitor of angiogenesis and tumor growth. Cell. 88:277-285. 